Canadian

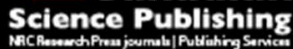

Canadian Geotechnical Journal Revue canadienne de géotechnique

\title{
Development of an Excavatability Test for Backfill Materials, Numerical and Experimental Studies
}

\begin{tabular}{|r|l|}
\hline Journal: & Canadian Geotechnical Journal \\
\hline Manuscript ID & cgj-2016-0534.R1 \\
\hline Manuscript Type: & Article \\
\hline Date Submitted by the Author: & $26-$ Apr-2017 \\
\hline Complete List of Authors: & $\begin{array}{l}\text { Morin, Caroline; Centre d'Etudes et de Recherches de l'Industrie du beton } \\
\text { Sedran, Thierry; Ifsttar, MAST/MIT } \\
\text { de Larrard, François; LafargeHolcim Group } \\
\text { Dumontet, Hélène; UPMC } \\
\text { Murgier, Sylvain; EDF Centre d'Expertise et d'Inspection dans les Domaines } \\
\text { de la Realisation et de l'Exploitation } \\
\text { Hardy, Michel; Engie Lab } \\
\text { Dano, Christophe; University Grenoble Alpes, 3SR Lab. Grenoble }\end{array}$ \\
\hline Keyword: & $\begin{array}{l}\text { excavatability, impact energy, punching test, repeatability, cement treated } \\
\text { materials }\end{array}$ \\
\hline &
\end{tabular}




\section{Development of an Excavatability Test for Backfill Materials \\ Numerical and Experimental Studies}

Caroline Morin, Thierry Sedran, François de Larrard, Hélène Dumontet, Michel Hardy, Sylvain Murgier, Christophe Dano

Caroline Morin,

CERIB, 1 rue des Longs Réages, CS 10010, 28233 Épernon Cedex, France

Thierry Sedran (corresponding author),

Ifsttar, route de Bouaye, CS 4, 44344 Bouguenais Cedex, France

tél. $+33(0) 240845632$

fax $+33(0) 240845994$

e-mail:thierry.sedran@ifsttar.fr

François de Larrard,

LCR - LafargeHolcim Group, 95 rue du Montmurier BP 70, 38291 Saint Quentin Fallavier Cedex, France

Hélène Dumontet, Institut Jean le Rond d'Alembert, Université Pierre et Marie Curie, Boîte 162, Tour 55-65, 4 place Jussieu, 75252 Paris Cedex 05, France

Sylvain Murgier,

EDF/CEIDRE, 2, rue Ampère - 93206 Saint-Denis Cedex 01, France

Michel Hardy,

Engie Lab, 361, Avenue du Président Wilson, B.P. 33, 93210 St Denis La Plaine Cedex,

France

Christophe Dano,

Université Grenoble Alpes, Laboratoire 3SR, Domaine Universitaire, BP53, 38041 Grenoble

Cedex 9 -France

Approximate words number: 5800 (with tables and figures) 


\section{Abstract}

This paper describes research done on a new testing device including its laboratory test procedure, namely a laboratory punching test for cementitious backfill materials to evaluate their excavatability with a pick. 3D and 2D numerical studies in using a finite element method were carried out according to calibrated parameters of the material obtained by triaxial tests. This made it possible to study the behavior of the backfill material under action induced by a tool (a pick) as well as to optimize the geometry of the punching test specimen. This paper provides detailed information and results for the experimental study of this laboratory test. Attention was particularly focused on energy relating to displacement as well as types of ruptures. The behavior of these types of material was found to be greatly influenced by gravel in the material. Repeatability of the test was also studied. Finally, a method for this punching test of backfill materials is also provided.

Keywords: cement treated materials, excavatability, impact energy, punching test, repeatability

\section{Introduction}

CLSMs have the specificity of being self-leveling and have a non-confined compressive strength lower than $8 \mathrm{MPa}$ (ACI 2009). Used as backfill materials, they make it possible to reduce trench widths and limit excavated earth, skilled labor, compacting and controls. This point is of interest for a gas supplier like Engie, but these materials, made of cementitious binder, must be excavatable (easily removable) on the long-term because when a leak appears on a gas distribution network, rapid intervention has to take place, with limited disturbance to 
the neighborhood. Unfortunately, today the assessment of this excavatability is still an unsolved important issue.

Currently, a first classification can be done based on observed in situ ratings of excavation, but this approach is not predictive. The non-confined compressive strength is certainly the most common means of assessing excavatability presented in literature, used directly (ACI 2009; Crouch et al. 1998; Pons et al. 1998; Bonnet at al. 1998), or integrated in index like the removability index (Du et al. 2002). A maximum value of $2 \mathrm{MPa}$ in compressive strength to ensure excavatability is generally reported (Bonnet el al. 1998) but this threshold does not refer to the power of the digging facility. Moreover, practical experiences show that two materials having the same compressive strength can behave very differently in a full-scale excavation test. Therefore this empirical strength criterion is clearly not sufficient. A classification based on the cone resistance obtained with a small penetrometer is proposed in (Manfoubie 1998). Although promising, this test is more dedicated to in situ evaluation, the results are quite dispersed and the proposed criteria are not widely validated. Finally a laboratory dynamic punching test is proposed (Rossi 2000). But the author does not mention information on the repeatability of the test. Moreover the test is made on unconfined small samples (although trenches are confined in a pavement), and is strongly related to compressive strength. Finally, proposed criterion was tested on only one material. Then relevance of the test can be questioned.

The aim of this paper is therefore to describe the development of a laboratory test to evaluate the excavatability of backfill materials. Generally, two fundamental earthmoving phases during material excavation, namely penetration of a tool and cutting and removal of material by movements of the tool in the material should be mentioned. This paper will focus on manual excavation with a pick because it was shown that the first phase was the critical one in 
terms of energy with a value of approximately $300 \mathrm{~J}$ at the impact of the pick (Morin, 2009).

Thus, assuming that the dynamic aspect is not predominant, a quasi-static test

by penetration of a punch in a cylindrical specimen that is confined in a mold was developed.

This paper will begin by presenting the production and mechanical characterization of a verylean concrete for trench backfilling.

Then, a parametric numerical analysis was carried out to compare the behavior of backfill materials placed in a trench surrounded by soil and subjected to the impact of a pick on one hand, and in the punching test, on the other hand. The geometry and configuration of the specimen was thus adapted to have a good correspondence of the two simulated behaviors.

Once the geometry selected, experimental research using statistical analyses was then carried out to determine feasibility and the necessary number of test repetitions; a test method was finally developed.

\section{Material testing}

A very-lean concretes (VLC), classically used for trench backfilling was first developed. The mixture proportions were determined to ensure a self compacting ability and a compressive strength lower than $2 \mathrm{MPa}$ to ensure excavatability (see Table 1).

Three batches of approximately 55 liters were made in a concrete mixer, to produce a sufficient number of samples for repeatability purposes of the punching test and strength measurements. The specimens were kept in their mold and stored at $20^{\circ} \mathrm{C}$ for 28 days.

Drained and consolidated triaxial tests were carried out according to the French AFNOR (NF P 94-074 Standard 1994) to characterize the behavior of the material and furnish the relevant parameters for the numerical calculation. The dimensions of the cylindrical specimens (diameter $110 \mathrm{~mm}$, height $220 \mathrm{~mm}$ ) were a compromise between the decision to use coarse aggregates $(14 \mathrm{~mm})$ and the dimensions of the $200 \mathrm{kN}$ testing machine. The samples were 
submitted to 3 different confining stresses $(100,200$ and $400 \mathrm{kPa}$, respectively) remaining constant while the deviatoric stress was increased until failure or substantial strain. The shear rate was $0.1 \mathrm{~mm} / \mathrm{min}$ for all the tests.

In order to simplify the numerical calculations a simple Mohr-Coulomb was used to analyze the results. The parameters thus obtained are presented in Table 2. The agreement of the fitting between experimental and theoretical curves is shown on Figure 1.

The high friction angle $\left(47^{\circ}\right)$ obtained for the very lean concrete could be explained by its granular skeleton. It is interesting to note that fluid mortars, which are also used as backfill materials, have a lower friction angle: $40^{\circ}$ (Hitch et al. 2004), $36^{\circ}$ (Morin 2009).

\section{Numerical simulation of the penetration process}

The main objective of this numerical study was to determine the most suitable geometries and configuration for the test specimens to be used in the experimental studies of excavatability carried out in the laboratory.

With this aim, the numerical study was divided into two parts. The behavior of backfill materials placed in a trench surrounded by soil and subjected to the impact of a pick was studied in the first part (the load was then distributed on a rectangular surface). Modeling was three-dimensional to study the influence of the surrounding material and take the shape of the tool and configuration of the trench into consideration.

The second part of the numerical study was devoted to simulating a cylindrical punching test in 2D axi-symmetric conditions to design the dimensions of the specimen test according to the three-dimensional 3D numerical results. 
Applied load vs penetration depth curves were obtained in both studies when penetration speed was imposed. From the area under these curves, energy vs penetration depth curves were then determined. Energy was particularly studied in the present paper because it is the single parameter that allows a rational comparison between the effect of a pick impact and the penetration of a punch. These latter curves were then compared and used to show the relevance of the punching test.

The results are presented in terms of energy penetration curves as a function of the imposed displacement. Energy is defined as the area under the force-penetration curve.

The development of tools to simulate the penetration process was not undertaken because the numerical developments would have been too complex.

Several authors were found in literature to have attempted to model the penetration process, for example the cone penetration test (Van den Berg 1994; Huang et al. 2004; Markauskas et al. 2002), the pile load test (Dijkstra et al. 2006 and Wehnert and Vermeer 2004) and indentation tests (Huang et al. 1998). However, the simulation of important deformations involved in the penetration process is still a challenging issue today. Two methods are generally used: the Lagrangian, and the Eulerian formulations. An Arbitrary LagrangianEulerian (ALE) scheme can be adopted to avoid frequent re-meshing in a large strain finite element calculation, thus making it possible to preserve the quality of the mesh throughout the numerical simulation (Nazem et al. 2007).

The numerical work was carried out using the Plaxis ${ }^{\mathrm{TM}} 3 \mathrm{D}$ Tunnel and Plaxis ${ }^{\mathrm{TM}} 2 \mathrm{D}$ v.8.2 software, for finite element calculations of important deformations (limited to intermediate strains, approximately $10 \%$ ). The stiffness matrix was based on the deformed geometry and updated at the beginning of a load step. Additionally, a special definition of stress rates was adopted including rotation terms. The co-rotational rate of the Kirchhoff stress (otherwise known as the Hill stress rate) was adopted in Plaxis ${ }^{\mathrm{TM}}$. Moreover, the finite element mesh was 
automatically updated as the calculation proceeded. These calculation procedures were based on an approach called "Updated Lagrange Formulation" (Nagtegaal and Jong 1981). The penetration of the tool in the material was assumed to be simulated in a static approach by imposed displacements. Therefore, no interface element was used. This test was carried out at a constant speed, thus favoring a static approach, while the impact of a pick tool usually occurred at speeds of approximately $14 \mathrm{~m} / \mathrm{s}$ (Morin 2009). However, Mishnaevsky reported that the process of breaking rocks remained roughly the same for speeds of around $8-10 \mathrm{~m} / \mathrm{s}$ regardless of the load, (dynamic or static), and justified this type of loading (Mishnaevsky 1995).

\section{Calculation results on a trench}

\section{Model description}

The geometric model was composed of a trench and surrounding material (soil and cementtreated material simulating a classical pavement base). Due to the symmetric geometry of the model, only one quarter of the model was simulated but all the results took the complete model into account. The dimensions of the 3D model are presented Figure 2. Lt and Lc were varied to study the effect of the trench width and the cement-treated materials. Simulations obtained for one value of each dimension are presented in this paper. The length of confinement Lc was determined to be sufficiently important so as not to influence results in the trench, i.e. more than three times the length of the 500-mm trench. Vertically-imposed displacement was applied on an area of $20 * 2 \mathrm{~mm}^{2}$ (representing a quarter of the $160 \mathrm{~mm}^{2}$ area of a real pick).

Finite element mesh and boundary conditions 
15-node wedge elements in 3 dimensions, composed of 6-node triangles in the $x-y$ directions and 8-node quadrilaterals in the z-direction, were selected to represent the very-lean concrete, the cement-treated material and the soil in the finite element model.

The boundary conditions of the model were:

- Bottom base nodes, at $\mathrm{Y}=0$, were fully constrained;

- Nodes on the vertical boundaries parallel to the $X-Y$ plane, at $Z=0$ and $Z=W 1$ (symmetry plane), were constrained in the lateral direction along the $\mathrm{Z}$ axis;

- Nodes on the vertical boundaries parallel to the $\mathrm{Y}-\mathrm{Z}$ plane, at $\mathrm{X}=0$ and $\mathrm{X}=\mathrm{Lc}+\mathrm{Lt}$ were constrained in the horizontal direction along the $\mathrm{X}$ axis;

The model was meshed so that the mesh density increased near the contact zone. Different densities meshes were tested on a preliminary simulation, in order to optimize the accuracy of the results, while keeping the calculation time acceptable. Finally, the following densities were selected for the trench (see Figure 3): 3768 elements for the very-lean concrete, 2616 elements for the cement-treated material and 1048 elements for the soil.

These densities were chosen because when denser ones were used, the simulation gave almost the same penetration depth-load curve (i.e. the same penetration depth-energy curve). The choice of the mesh density for the VLC was more deeply justify by verifying that the simulation can predict, with an error less than $1 \%$, the analytical pressure limit obtained in the simplified case of an homogeneous pressure on a Mohr-Coulomb material, by the following equation (Mestat 1994):

$P_{\text {lim }}=C \operatorname{cotg}(\varphi)\left[e^{\pi \operatorname{tg}(\varphi)} \operatorname{tg}^{2}\left(\frac{\pi}{4}+\frac{\varphi}{2}\right)-1\right], \mathrm{C}$ the cohesion and $\varphi$ the friction angle. Eq. 1

\section{Materials model}

As explain in paragraph Material Testing, the elasto-plastic model using a Mohr-Coulomb criterion, implemented in the PLAXIS software, was used to describe the behavior of the 
very-lean concrete material. Table 2 summarizes the elasto-plastic model parameters measured on the very-lean concrete material as well as the typical elastic model parameters of soil and cement-treated material surrounding the trench.

\section{Calculations results on a punch test}

\section{Model description}

The specimen is a cylinder confined in a mold. The 2D axi-symmetric model dimensions, which is a three dimensional model, is presented in Figure 4, where " $\mathrm{H}$ " is the height of the specimen, " $\mathrm{D}$ " is the diameter of the specimen, " $\mathrm{d}$ " the diameter of the loading area, "e" the thickness of the mold. Vertically-imposed displacement was applied on a radius of $7 \mathrm{~mm}$, corresponding to a $14 \mathrm{~mm}$ punch having almost the same area as the pick used in the previous three-dimensional simulations of a trench.

\section{Finite mesh and boundary conditions}

The punching test was modeled by the static elasto-plastic, large-strain finite element method (FEM) using triangular 6-node elements. Refining mesh consisted of increasing the elements' density under the application of the vertically-imposed displacement.

As explained before for trench calculation, a preliminary optimization of the meshes densities was carried out. Three levels were tested with a total of 1171,1624 and 3125 elements respectively. Finally the following densities were selected as shown in Figure 4: 2724 elements for the very-lean concrete and 401 for the steel mold. The Young modulus of the steel was considered to be equal to $210000 \mathrm{MPa}$, with a Poisson ratio of 0.3 . Molds were not produced in plastic because calculations showed that plastic was less suitable to reproduce the stiffness of the surrounding soil and did not allow for repeated use of the mold, contrary to steel molds

The boundary conditions of the model were: 
- $\quad$ The bottom base nodes, at $Y=0$, were fully constrained;

- The nodes on the vertical boundaries parallel to the $\mathrm{Y}$ axis, at $\mathrm{X}=0$ were anchored in the $\mathrm{x}$ direction;

- The nodes on the vertical boundaries parallel to the $\mathrm{Y}$ axis, at $\mathrm{X}=\mathrm{D} / 2+\mathrm{ep}$ were free.

Results

This section deals with the dimensions of the punching test, i.e. H (height) and D (diameter). Various combinations were tested to determine these dimensions. The influence of $\mathrm{H}$ was first studied. The values of $\mathrm{H} / \mathrm{d}$ in the calculations, $(\mathrm{d}=$ the diameter corresponding to the area on which the load is applied) were in the range of 11.4, 17.4 and 22.8 (i.e. $\mathrm{H}=160,240$ and 320 $\mathrm{mm}$ ). The results showed no influence of these ratios on the energy vs penetration depth curves. Similarly, the calculations were based on various values of $D$ to determine the proper diameter $\mathrm{D}$ of the specimen $(120,160$ and $240 \mathrm{~mm}$, corresponding to $\mathrm{D} / \mathrm{d}$ values of $8.6,11.4$ and 17.4, respectively). The results showed no difference between these selected ratios. However, the volume of the specimen had to be representative of the material. This is a complex issue, but it is usually resolved by imposing that the minimum size of a sample is five times more than the maximum size of the aggregates. If, in practice, the maximum size of the aggregates is smaller than $31.5 \mathrm{~mm}$, a dimension of $160 \mathrm{~mm}$ fits the requirement. Finally, diameter $\mathrm{D}$ of $160 \mathrm{~mm}$ and a height $\mathrm{H}$ of $160 \mathrm{~mm}$ were selected

The effect of the confinement exerted by the steel mold on the cementitious material was studied by varying the thicknesses of the mold between 4 and $10 \mathrm{~mm}$. As shown in Figure 5, the confinement had a considerable effect on the energy-displacement curve. This shows that the choice of the confining specimens is important because it will prevent premature splitting failure of the specimen. The thickness of the mold $(4 \mathrm{~mm})$ appeared to be sufficient and is practical because it is available on the market. 


\section{Comparison between 3D and 2D axi-symmetrical simulations}

To conclude, the dimensions of the punching test specimen were fixed as following, with a punch of $14 \mathrm{~mm}$ in diameter d: $160 \mathrm{~mm}$ height $\mathrm{H}, 160 \mathrm{~mm}$ diameter $\mathrm{D}$ and a confinement exerted by a steel, 4 mm-thick mold. In this configuration, we can see in Figure 6 that the numerical curves obtained in 2D on punching test and in 3D on trench are superimposed for the selected very lean concrete, until reaching a displacement of $10 \mathrm{~mm}$, where the 3D calculations stopped due to excessive mesh distortion. Even if the energy did not exceed $70 \mathrm{~J}$ in these simulations, while a real pick impact involves rather 300J (Morin 2009), this good agreement was estimated relevant enough to validate the selected geometry of the punching test device and start an experimental validation.

\section{Experimental studies using the punch test}

The purpose of this initial experimental campaign of the punch test was to evaluate the feasibility and reliability of this test on VLC.

\section{Experimental device and testing procedure}

A flat-bottomed circular punch was used to load the flat surfaces of the specimens. It was designed to match the area of a real tool. A diameter of $14 \mathrm{~mm}$ was therefore determined. Such a flat-bottomed circular punch was chosen to obtain repeatable and consistent results, compared to a rectangular punch. A stiff displacement-controlled, $100 \mathrm{kN}$ compressive testing machine was used to load the punch normally against the surfaces of the specimen. Load was applied at a constant speed of $9.5 \mathrm{~mm} / \mathrm{min}$, the maximum speed allowed by the machine; it was measured using a load sensor. The penetration depth was monitored by a LVDT, 
mounted between the specimen and the plate of the press. The measurement range of the displacement sensor was 0-80 $\mathrm{mm}$. Figure 7 shows the test device.

The output voltages from the devices were then monitored using a computer and software, GDSLab, giving a real time plot of load vs penetration data. The load-penetration depth curve (material failure signature) graphed during the test provided a visual picture of the loading history of indentation during the test. After integrating this curve, the energy carried out during the penetration process could be plotted (i.e. the area under the curve loadpenetration). The type of rupture in the sample during the test was also observed.

\section{Testing program}

18 samples (Ø $160 \mathrm{~mm} \times 160 \mathrm{~mm}$ ) were cast in $4 \mathrm{~mm}$-thick molds according to the numerical study. The very lean concrete was produced in three batches, according to the capacity of the mixer. The specimens were kept in their steel mold and stored at $20^{\circ} \mathrm{C}$ for 28 days.

\section{Test results and discussions}

Several means of processing data from the punching test are described in literature. Dollinger et al. (Dollinger et al. 1998) reported a method involving drawing the linear regression line on the force-penetration graph through the origin and force-penetration data and then directly estimating the expected load and penetration from this line during excavation using the slope of the line (called as the "Penetration Index"). However, this method was not applicable to the results of this study because the relationship between the load and penetration depth was not linear as shown in Figure 8. So, the curves were integrated to obtain energy-penetration depth curves as shown in Figure 9.

On Figure 8, curves generally display non-monotonic increase of load while penetration is increasing. As coarse aggregates are the hardest part of the very lean concrete (VLC), they 
may easily peel away from the paste and rotate when pushed by the punch. This lead to chips occurrence as shown on Figure 10, and sudden decrease of load. This is the main mechanism allowing penetration. The scattering between the different energy curves may be explained by a normal variation in the number of aggregates encountered by the punch during its penetration. This scattering is probably increased because VLC are very fluid and may display some segregation.

As a confirmation of these explanations, similar tests were done on mortar with high amount of air entrained. In that context, the main penetration process is the compaction of the material under the punch allowed by the presence of air voids, with no chips (Figure 11a). Therefore, the penetration depth-energy curves are less scattered and more regular (Morin 2009), as shown in Figure $11 \mathrm{~b}$.

In conclusion, the coarse aggregate particles play an important role in this type of material and the load-penetration curve is an indication of several phenomena. A lack of confinement could have induced a change in the failure process of the material, beginning with the formation of chips and leading to a vertical axial splitting failure.

Finally, Figure 9 shows that energy reached $150 \mathrm{~J}$ for a depth penetration of $10 \mathrm{~mm}$ that is higher than given by numerical calculations. It even reached 300 to $600 \mathrm{~J}$ for $40 \mathrm{~mm}$. This underlies that the model used to describe the material in simulations might not completely capture its behavior, during a penetration process due to its granular nature.

\section{Repeatability of the punching test}

The aim of this study was to determine the repeatability (NF ISO 5725-1 2005) of the test and more precisely the number of specimens needed to test a material. During the experiments, 
the same material was used for all the specimens and only one operator was in charge of the tests. Speed measurements, carried out using a high-speed camera filming the operators using a pick showed that the energy ranged from $70 \mathrm{~J}$ for one operator (a woman) to $350 \mathrm{~J}$ for strong operators (men) (Morin 2009). The penetration depth $(u)$ at 100, 200 and $300 \mathrm{~J}$ for the VLC were therefore studied and a statistical study was carried out on $u$ for a given level of energy. Table 3 shows the results obtained in the punching tests. It can be observed that the standard deviation increased as the level of energy increased.

A variable called $t$ was then introduced for the statistical analyses.

$t=\frac{u_{m e a n}-m}{\frac{s}{\sqrt{n}}}$

$t$ is a Student variable with a number of degrees of freedom equal to $(n-1)$, where $u_{\text {mean }}$ is the real mean value of the penetration, $m$ the estimation of the mean value obtained experimentally on $n$ specimens and $s$ the standard deviation.

The confidence interval of $m$ with a risk $\alpha$ is given by

$u_{\text {mean }}-t_{1-\frac{\alpha}{2}} \frac{s}{\sqrt{n}}<m<u_{\text {mean }}+t_{1-\frac{\alpha}{2}} \frac{s}{\sqrt{n}}$

where $t_{1-\frac{\alpha}{2}}$ is read in the Student table.

In the present case, for $n=6$ and a risk of $10 \%$ this value is 1.74 . Thus if we want to ensure at $90 \%$ that the mean penetration is obtained by the punching test with an error less than $10 \%$, the number of samples $\mathrm{n}$ should verify (under the assumption that $t_{1-\frac{\alpha}{2}}$ and $s$ keep constants)

$n \geq\left(\frac{t_{1-\frac{\alpha}{2}} s}{0.1 u_{\text {mean }}}\right)^{2}$

Eq. 4

When considering the value $u$ at $300 \mathrm{~J}$, corresponding to approximately the real impact energy given by a pick, 6 specimens are then necessary to have a relevant result. 


\section{Proposition of a test procedure}

Previously presented work showed that the punching test could be made for backfill materials, such as VLC using a stiff displacement-controlled, $100 \mathrm{kN}$ machine, at a maximum constant speed of $9.5 \mathrm{~mm} / \mathrm{min}$ and a displacement sensor of $80 \mathrm{~mm}$. Materials must be prepared in steel molds ( thickness: $4 \mathrm{~mm}$ ) to ensure sufficient confinement. The force-displacement curve must be monitored during the test to then plot the energy-displacement curve. This test requires the production of 40 liters (minimum) of material to produce at least 6 samples for testing. Furthermore, strength characterization of the material should be carried out (compressive, tensile strength tests).

\section{Conclusions}

The purpose of this paper is to present the setting-up conditions of a new laboratory test, namely a punching test for backfill materials. The purpose of this test is to determine the excavatability of small specimens in the laboratory.

First of all, excavation movement by a pick was analyzed to determine the fundamental variables that could then be exploited. Two actions were specified: the first corresponds to penetration of the pick in the material for a given amount of energy. The second entails cutting and removing the material. At this latter stage the torque and extracted volume determine the excavatability level of the material. The present paper has focused on the first part of the excavation process, as it was shown that it is the most energy consuming part.

One type of backfill materials was formulated in the second part of this paper, i.e. a very lean concrete. The specificity of the latter lies in its coarse skeleton compared to other types of materials, for example mortars with high percentage of entrained air. The material was subjected to compressive, tensile and triaxial tests. The latter tests made it possible to 
calibrate the parameters of the Mohr-Coulomb model. Another law could be used to better describe the behavior of the material, for example the Hardening Soil model.

A numerical study was then carried out on the penetration process of a pick in a trench and of a punch in a laboratory sample using $3 \mathrm{D}$ and $2 \mathrm{D}$ Plaxis $^{\mathrm{TM}}$ software calculations respectively, to design the laboratory test. A static approach with prescribed penetration depth was adopted coupled with the Updated Lagrangian Method. A parametric study of the sample's dimensions was carried out to determine the dimensions and necessary confinement to obtain the same energy-penetration curves already obtained in the 3D. Results showed that the $3 \mathrm{D}$ results and 2D results were very similar for a specimen with the following requirement: $160 \mathrm{~mm}$ height, $160 \mathrm{~mm}$ diameter, confined in a $4 \mathrm{~mm}$ thick steel mold.

Finally, experimental studies of the punching test were carried out on the very lean concrete. The results obtained for the concrete were scattered due to the high proportions of aggregates. According to the statistical study, in order to estimate, with a $90 \%$ probability of having less than $10 \%$ error, the mean value of the statistical variable (penetration), six tests specimens are necessary.

The punching test was designed with quasi-static simulations, while pick can reach $14 \mathrm{~m} / \mathrm{s}$ at the impact. Nevertheless, based on the present work, several mixtures with different compositions were tested with this punching test. They confirmed, that the punch penetration is strongly correlated to pick penetration during real scale excavation, provided the same energy is used in both cases (Morin et al. 2013), (Gennesseaux 2015), justifying a posteriori the assumptions made in the simulations.

\section{Acknowledgements}

The main author acknowledges Vey T. for a bibliography made during a training period before the beginning of the $\mathrm{PhD}$ on excavatability (Vey 2006). 


\section{References}

ACI. Controlled Low-Strength Materials. American Concrete Institute 229R-99. Farmington Hills, Michigan, 2009.

Bonnet, G., Gavalda, A., and Quibel, A. 1998. Remblayage des tranchées, Utilisation de matériaux autocompactants. Etat des connaissances. Dossier Certu, No 78, 36 pages.

Crouch, L.K., Dotson, V.J., Badoe, D.A., Maxwell, R.A., Dunn, T.R., and Sparkman, A. 1998. Long term study of 23 excavatable Tennessee fill mixtures. The Design and Application of Controlled Low-Strength Materials (Flowable Fill), ASTM STP 1331, Howard A.K. and Hitch, J.L., Eds., American Society for Testing and Materials.

Dijkstra, J., Broere, W., and van Tol, A.E. 2006. Numerical investigation into stress and strain development around a displacement pile in sand. Sixth European Conference on Numerical Methods in Geotechnical Engineering, Graz, Austria.

Dollinger, G.L., Handewith, H.J., and Breeds C.D. 1998. Use of the Punch Test for Estimating TBM Performance. Tunnelling and Underground Space Technology 13, No. 4, 403-408.

Du, L., Folliard, K.J., and Trejo, D. 2002. Effects of constituent materials and quantities on water demand and compressive strength of controlled low-strength material. Journal of Materials in Civil Engineering 14, No. 6, 2002, 485-495.

European Standards. NF ISO 5725-1 1994. Application de la statistique. Exactitude (justesse et fidélité) des résultats et méthodes de mesure. Partie 1: Principes généraux et définitions. AFNOR 1994.

European Standards. NF P 94-074 1994. Sols : reconnaissance et essais. Essais à l'appareil triaxial de révolution. Appareillage. Préparation des éprouvettes. Essai non consolidé non drainé. Essai consolidé drainé avec mesure de pression interstitielle. Essai consolidé drainé. AFNOR, 1994. 
Gennesseaux, E. 2015. Exacavabilité et formulation des matériaux traités aux liants hydrauliques pour tranchées, Doctoral thesis of UNAM, Nantes (in French).

Hitch, J.L., Howard, A.K., and Baas W.P. 2004. Innovations in controlled low-strength material (flowable fill). ASTM, STP 1459.

Huang, H., Damjanac, B., and Detournay, E. 1998. Normal wedge indentation in Rocks with lateral confinement. Rock Mechanics and Rock Engineering 31, No. 2, 81-94.

Huang, W., Sheng, D., Sloan, S.W., and Yu, H.S. 2004. Finite element analysis of cone penetration in cohesionless soil. Computers and Geotechnics 31, 517-528.

Manfoubie N. 1998. Contrôle de tranchées en béton autocompactant excavable à l'aide du PANDA. CUST, Département Génie Civil de l’Université Blaise Pascal. ClermontFerrand 2.

Markauskas, D., Kacianauskas, R., and Suksta, M. 2002. Modelling the cone penetration test by the finite element method. Foundations of Civil and Environmental Engineering, No. 2.

Mestat, P. 1993. Lois de comportement des géomatériaux et modélisation par la méthode des éléments finis. Etudes et recherches des LPC, No. GT 52, 194 p.

Mishnaevsky, L.L. 1995. Physical mechanisms of hard rock fragmentation under mechanical loading: a review. International Journal of Rock Mechanics and Mining Sciences \& Geomechanics Abstracts 32, No. 8, 763-766.

Morin, C. 2009. Etude de l'excavabilité des matériaux traités aux liants hydrauliques pour tranchées. Doctoral thesis of UPMC, Paris (in French).

Morin, C., Sedran, T., de Larrard, F., Dumontet, H., Murgier, S., Hardy, M., and Dano, C. 2013. Prediction of the volume of concrete backfill materials excavated with a pick, European Journal of Environmental and Civil Engineering, DOI: $10.1080 / 19648189.2013 .837012$ 
Nagtegaal, J.C., and Jong, J.E. 1981. Some computational aspects of elastic-plastic large strains analysis. International Journal for numerical methods in engineering 17, 1541.

Nazem, M., Sheng, D., Carter, J.P., and Sloan, S.W. 2008. Arbitrary Lagrangian-Eulerian method for large-strain consolidation problems. International Journal for Numerical and Analytical Methods in Geomechanics 32, 1023-1050.

Pons, F., Landwermeyer, J.S., and Kerns, L. 1998. Development of engineering properties for regular and quick-set flowable fill. In The Design and Application of Controlled LowStrength Materials (Flowable Fill), ASTM STP 1331. American Society for Testing and Materials.

Rossi, G. 2000. Indagine su una prova di demobiblita'di miscele betonabilit per riempimenti fluidi. Department of Idraulica, Transporti e Strade, University of Rome «La Sapienza », Italy, presentation au X Convegno S.I.IV., Catania.

Van den Berg, P. 1994. Analysis of soil penetration. Ph. D. Thesis, Delft University of Technology.

Vey, T. 2006. Etude préliminaire sur la réexcavabilité des matériaux hydrauliques. Stage ingénieur Ecole Centrale Nantes et LCPC (in French).

Wehnert, M., and Vermeer, P.A. 2004. Numerical Analyses of Load Tests on Bored Piles. NUMOG $9^{\text {th }}$, Ottawa, Canada.

\section{List of notations}

CLSM: Controlled Low Strength Materials

VLC: Very-Low Concrete

2D: two dimensional 
3D: three dimensional

$\mathrm{f}_{\mathrm{c}}$ : Compressive strength

$\mathrm{f}_{\mathrm{t}}$ : splitting tensile strength

q: deviatoric stress

Eps_1: axial strain

$\tau$ : shear stress on the failure plane

$\mathrm{C}$ : cohesion of the material

$\sigma:$ normal stress on the failure plane

$\varphi$ : angle of internal friction

$\psi:$ dilatancy angle

W1: lateral bound width

W2: contact zone length

W3: contact zone width

Lt: trench width

Lc: cement-treated width

ht: trench depth

$\mathrm{h}$ : depth of the surrounding material

E: Young's modulus

v: Poisson's ratio

$\mathrm{H}$ : height of the specimen

D: diameter of the specimen

$\mathrm{d}$ : diameter of the displacement punch

e: thickness of the mold

F: load

$\mathrm{u}, \mathrm{uy}$ : penetration, penetration in the direction of the $\mathrm{y}$-axis 
W: work (energy)

$u_{\text {mean }}$ : mean value of the given variable (penetration)

$n$ : number of specimens

$s$ : standard deviation of the given variable

$m$ : estimation of the mean value of the penetration

$t$ : Student variable with a number of degrees of freedom equal to $(n-1)$

\section{List of figures}

Figure 1: experimental and theoretical deviatoric stress (q)-strain (Eps_1) curves for the VLC

Figure 2: Trench and surrounding materials model dimensions (1/4 of the total model)

Figure 3: Finite element mesh for the trench and the surrounding materials

Figure 4: punching test: dimensions, finite element mesh and boundary conditions

Figure 5: effects of mold thickness on simulated energy-penetration depth curves. $0 \mathrm{~mm}$ means punching in unconfined conditions

Figure 6: comparison of energy-penetration depth curves resulting from trench 3D calculation on trench and 2D calculations on punching test for the same VLC

Figure 7: punching test device

Figure 8: load-penetration curves obtained with different samples of the same VLC

Figure 9: energy-penetration depth curves deduced from Figure 8

Figure 10: typical rupture of VLC

Figure 11: typical rupture of mortars with high volume of air entrained (a) and energypenetration depth curves on different samples of the same mortar (b) 


\section{List of tables}

Table 1: Mix proportions and properties of the very lean concrete

Table 2: Law parameters of the simulated materials

Table 3: penetration depth u obtained on the very lean concrete 
Table 1: Mix proportions and properties of the very lean concrete

\begin{tabular}{|c|c|}
\hline \multicolumn{2}{|l|}{ Composition } \\
\hline CEM I Cement $52.5(\mathrm{~kg})$ & 48 \\
\hline Limestone Filler (kg) & 86 \\
\hline 0/4 mm River Sand (kg) & 565 \\
\hline 6/10 Crushed Aggregates (kg) & 104 \\
\hline 10/14 Crushed Aggregates (kg) & 920 \\
\hline Water (kg) & 193 \\
\hline \multicolumn{2}{|l|}{ Properties } \\
\hline Specific gravity $\left(\mathrm{kg} / \mathrm{m}^{3}\right)$ & 2230 \\
\hline Air content $(\%)$ & 5 \\
\hline \multicolumn{2}{|l|}{ Non confined compression strength $\mathrm{f}_{\mathrm{c}}(\mathrm{MPa})$} \\
\hline Batch 1 & 0.910 \\
\hline Batch 2 & 0.710 \\
\hline Batch 3 & 0.831 \\
\hline Mean value & 0.817 \\
\hline \multicolumn{2}{|l|}{ Tensile strength $\mathrm{f}_{\mathrm{t}}(\mathrm{kPa})$} \\
\hline Batch 1 & 80 \\
\hline Batch 2 & 120 \\
\hline Batch 3 & 120 \\
\hline Mean value & 107 \\
\hline
\end{tabular}


Table 2: Law parameters of the simulated materials

\begin{tabular}{|l|l|}
\hline \multicolumn{2}{|l|}{ Elasto-plastic model parameters for the backfill material } \\
\hline Young modulus E [MPa] & 200 \\
\hline Poisson ratio $v$ & 0.2 \\
\hline Cohesion c [MPa] & 0.170 \\
\hline Angle of internal friction $\varphi\left[^{\circ}\right]$ & 47 \\
\hline Dilatancy angle $\left.\psi{ }^{\circ}{ }^{\circ}\right]$ & 14 \\
\hline $\mathrm{f}_{\mathrm{t}}[\mathrm{MPa}]$ & 0.100 \\
\hline $\mathrm{f}_{\mathrm{c}}[\mathrm{MPa}]$ & 0.740 \\
\hline Elastic model parameters for the soil & \\
\hline Young modulus E [MPa] & 50 \\
\hline Poisson ratio $v$ & 0.35 \\
\hline Elastic model parameters for the cement treated material \\
\hline Young modulus E [MPa] & 10000 \\
\hline Poisson ratio $v$ & 0.25 \\
\hline
\end{tabular}


Table 3: penetration depth u obtained on the very lean concrete

\begin{tabular}{|c|c|c|c|c|}
\hline \multicolumn{2}{|c|}{ Level of energy (J) } & 100 & 200 & 300 \\
\hline \multicolumn{2}{|c|}{ Batch/Specimen } & $u(\mathrm{~mm})$ & $u(\mathrm{~mm})$ & $u(\mathrm{~mm})$ \\
\hline \multirow[t]{6}{*}{1} & 1 & 13.8 & 24.0 & 34.2 \\
\hline & 2 & 11.5 & 18.9 & 26.3 \\
\hline & 3 & 17.3 & 27.5 & 34.7 \\
\hline & 4 & 15.5 & 24.6 & 32.6 \\
\hline & 5 & 11.5 & 19.4 & 27.5 \\
\hline & 6 & 14.0 & 21.3 & 29.2 \\
\hline \multirow[t]{6}{*}{2} & 1 & 12.5 & 21.1 & 26.9 \\
\hline & 2 & 12.4 & 19.8 & 26.8 \\
\hline & 3 & 11.3 & 17.0 & 22.2 \\
\hline & 4 & 11.2 & 18.1 & 23.9 \\
\hline & 5 & 8.9 & 14.8 & 21.7 \\
\hline & 6 & 10.0 & 16.9 & 24.6 \\
\hline \multirow[t]{6}{*}{3} & 1 & 10.4 & 16.1 & 22.3 \\
\hline & 2 & 12.7 & 21.1 & 29.2 \\
\hline & 3 & 13.2 & 22.3 & 30.8 \\
\hline & 4 & 16.0 & 23.9 & 31.9 \\
\hline & 5 & 14.4 & 22.8 & 30.2 \\
\hline & 6 & 12.1 & 20.1 & 30.3 \\
\hline \multicolumn{2}{|c|}{ Mean value $\mathrm{m}(\mathrm{mm})$} & 12.7 & 20.6 & 28.1 \\
\hline \multicolumn{2}{|c|}{ Standard deviation s (mm) } & 2.2 & 3.3 & 4.1 \\
\hline \multicolumn{2}{|c|}{ Coefficient of variation (\%) } & 17 & 16 & 15 \\
\hline
\end{tabular}




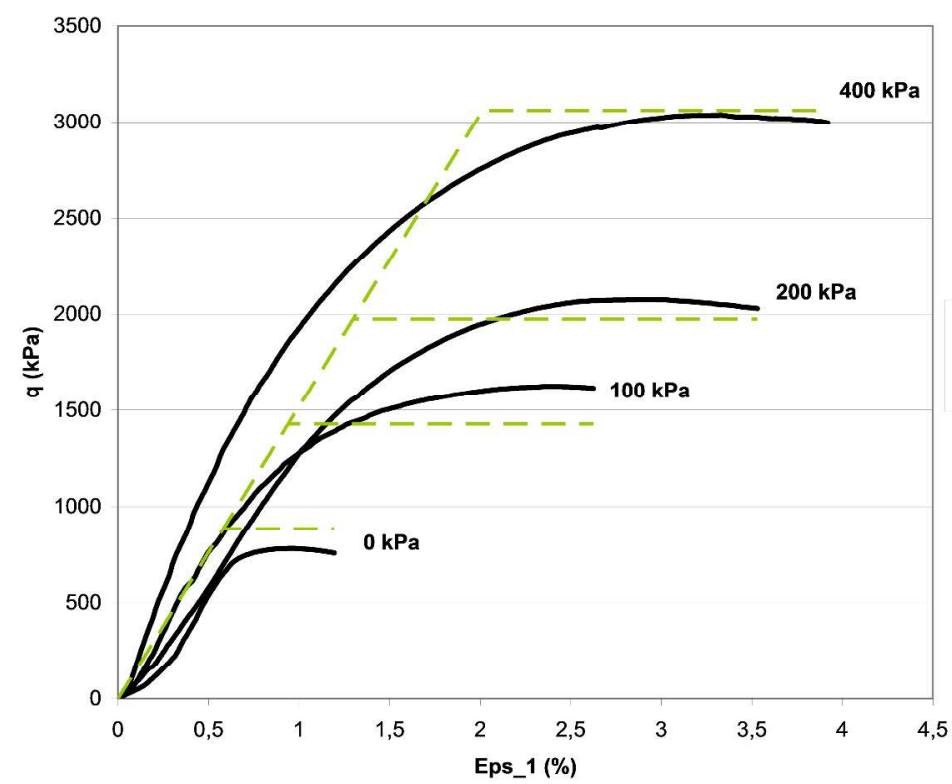

Experimental curve - Theoretical curve

Figure 1: experimental and theoretical deviatoric stress (q)-strain (Eps_1) curves for the VLC $512 \times 318 \mathrm{~mm}(300 \times 300 \mathrm{DPI})$ 


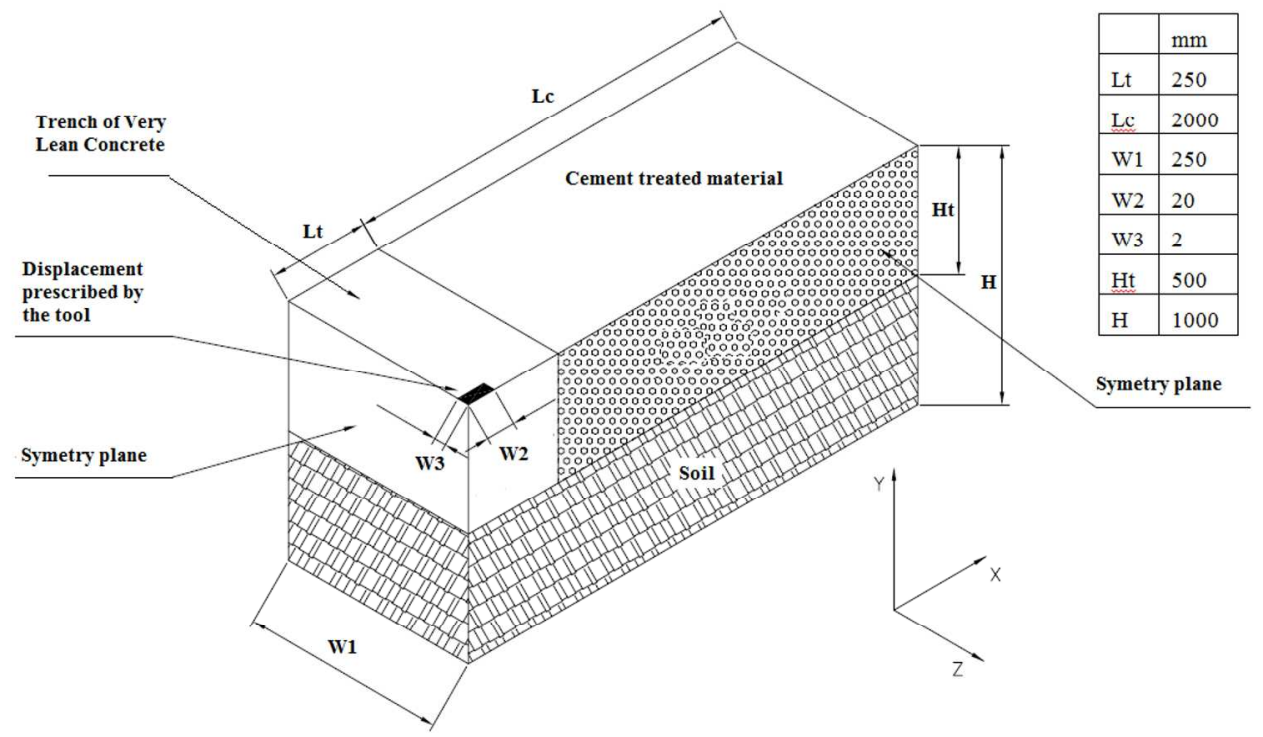

Figure 2: Trench and surrounding materials model dimensions (1/4 of the total model) $396 \times 231 \mathrm{~mm}(300 \times 300$ DPI) 

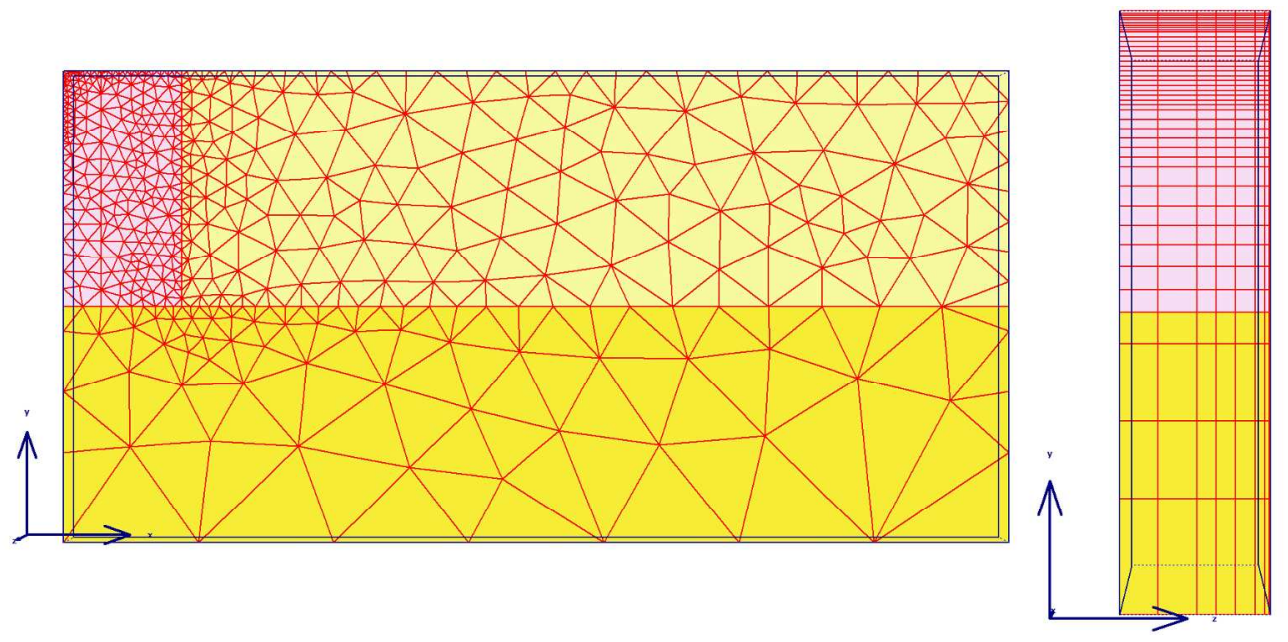

Figure 3: Finite element mesh for the trench and the surrounding materials $527 \times 254 \mathrm{~mm}(300 \times 300$ DPI) 

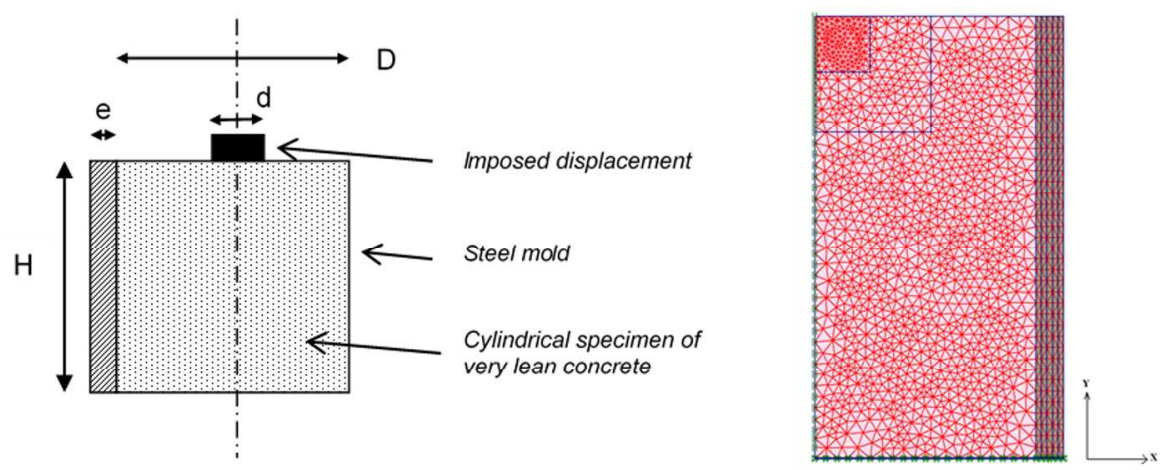

Figure 4: punching test: dimensions, finite element mesh and boundary conditions $308 \times 114 \mathrm{~mm}(300 \times 300 \mathrm{DPI})$ 


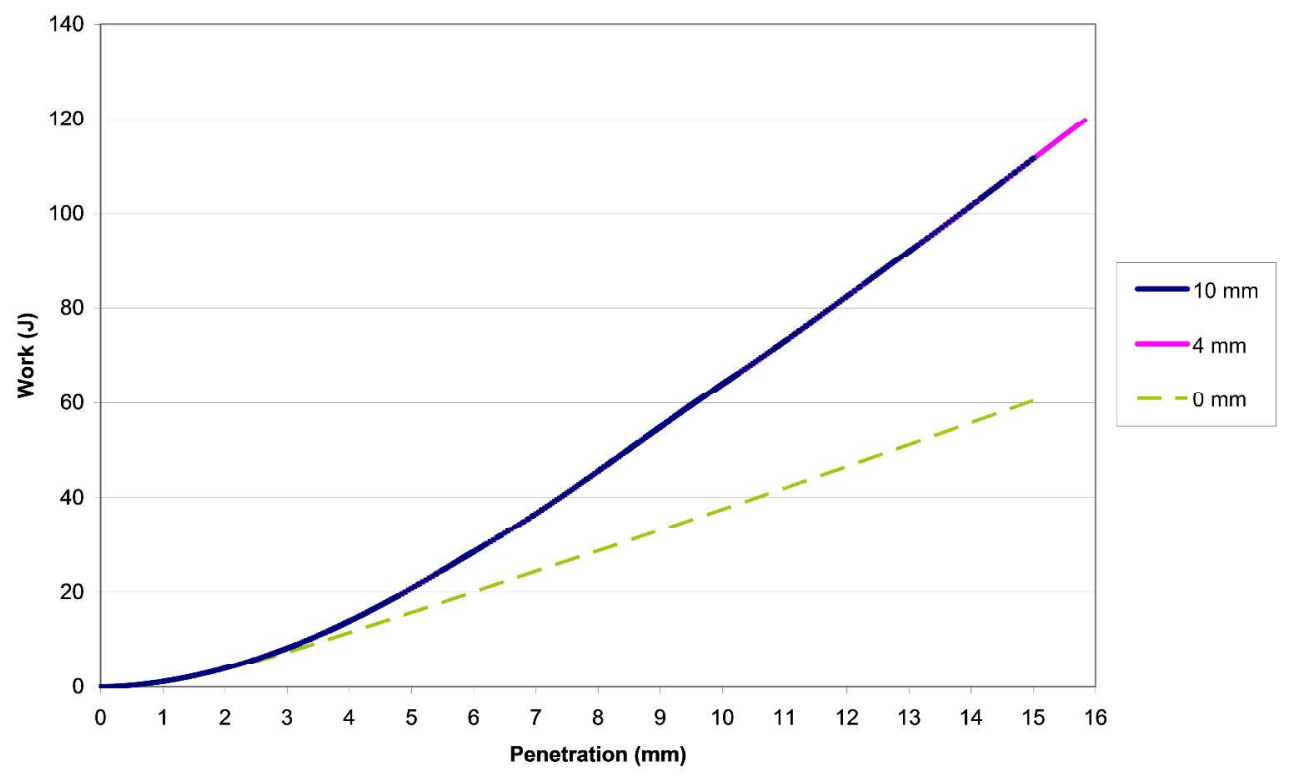

Figure 5: effects of mold thickness on simulated energy-penetration depth curves. $0 \mathrm{~mm}$ means punching in unconfined conditions

$512 \times 318 \mathrm{~mm}(300 \times 300 \mathrm{DPI})$ 


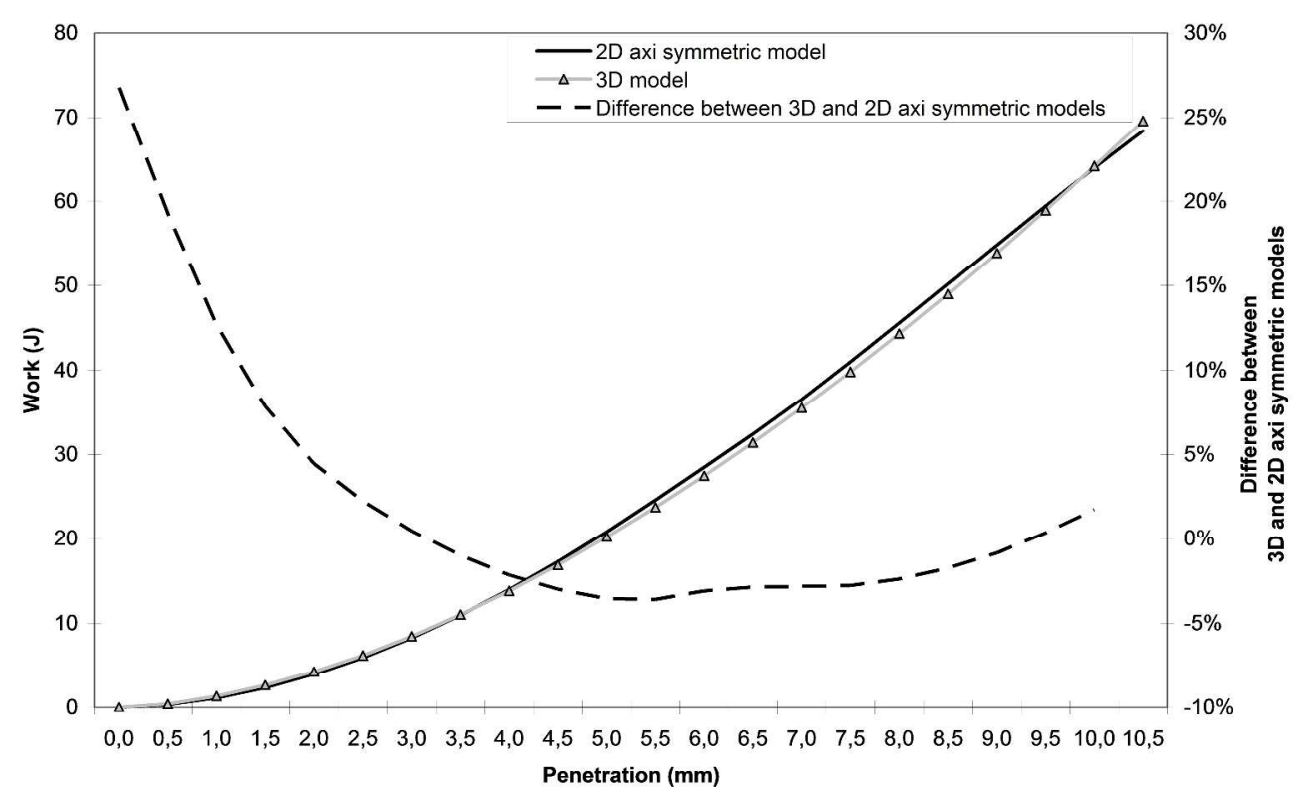

Figure 6: comparison of energy-penetration depth curves resulting from trench 3D calculation on trench and 2D calculations on punching test for the same VLC

$$
511 \times 318 \mathrm{~mm}(300 \times 300 \text { DPI) }
$$




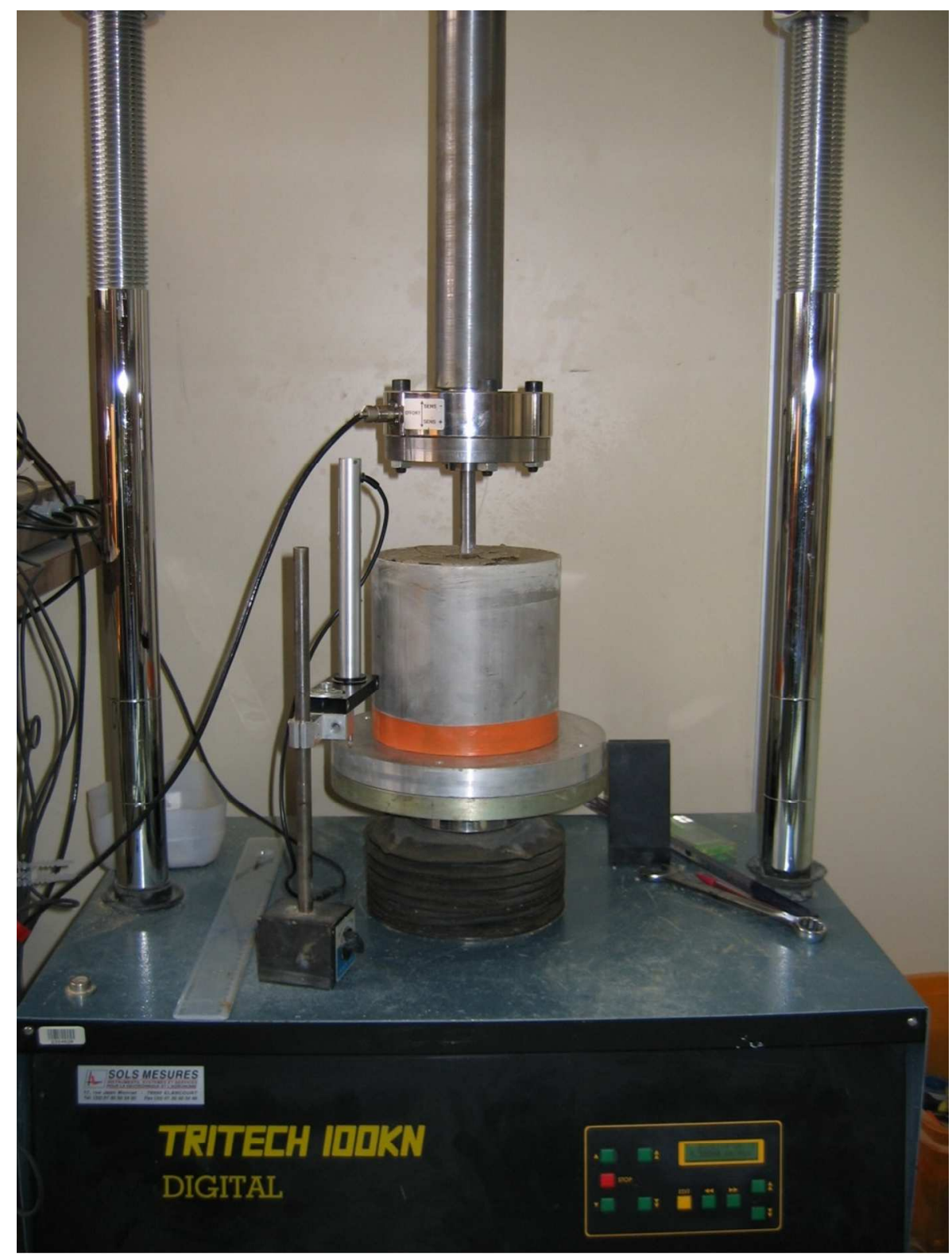

Figure 7: punching test device $131 \times 175 \mathrm{~mm}(300 \times 300 \mathrm{DPI})$ 


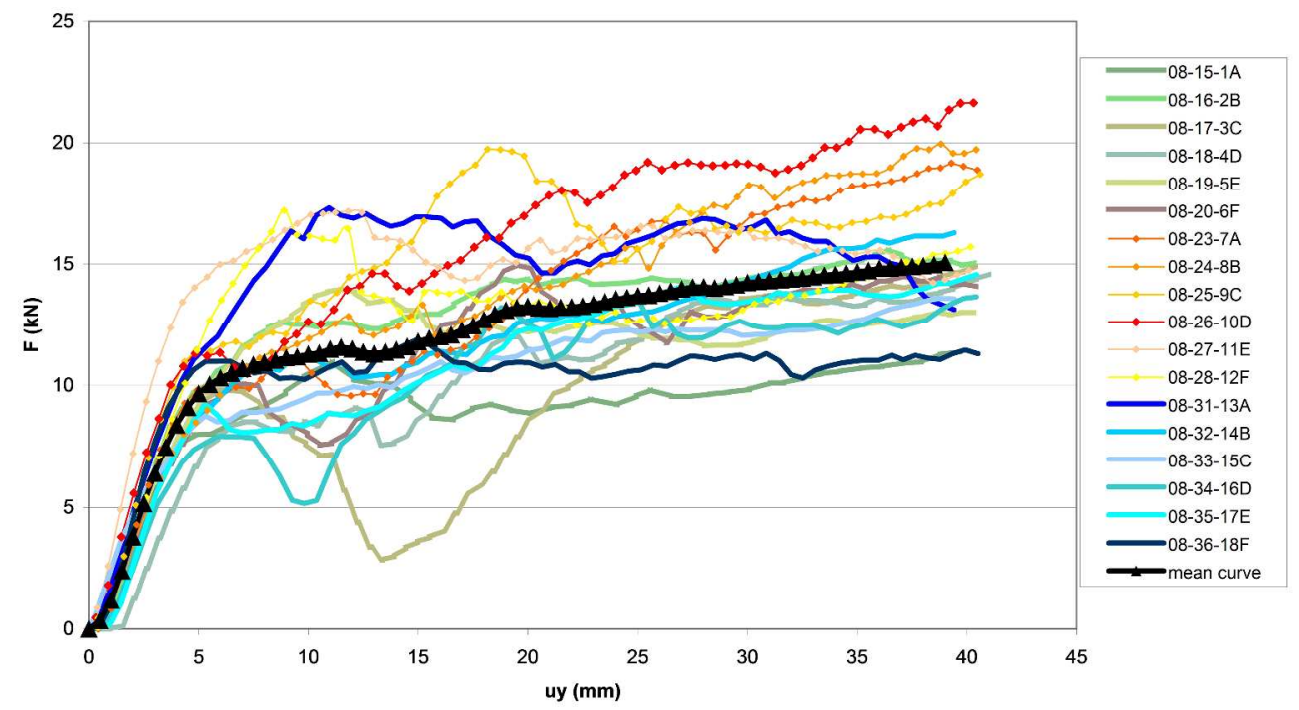

Figure 8: load-penetration curves obtained with different samples of the same VLC $514 \times 318 \mathrm{~mm}(300 \times 300 \mathrm{DPI})$ 


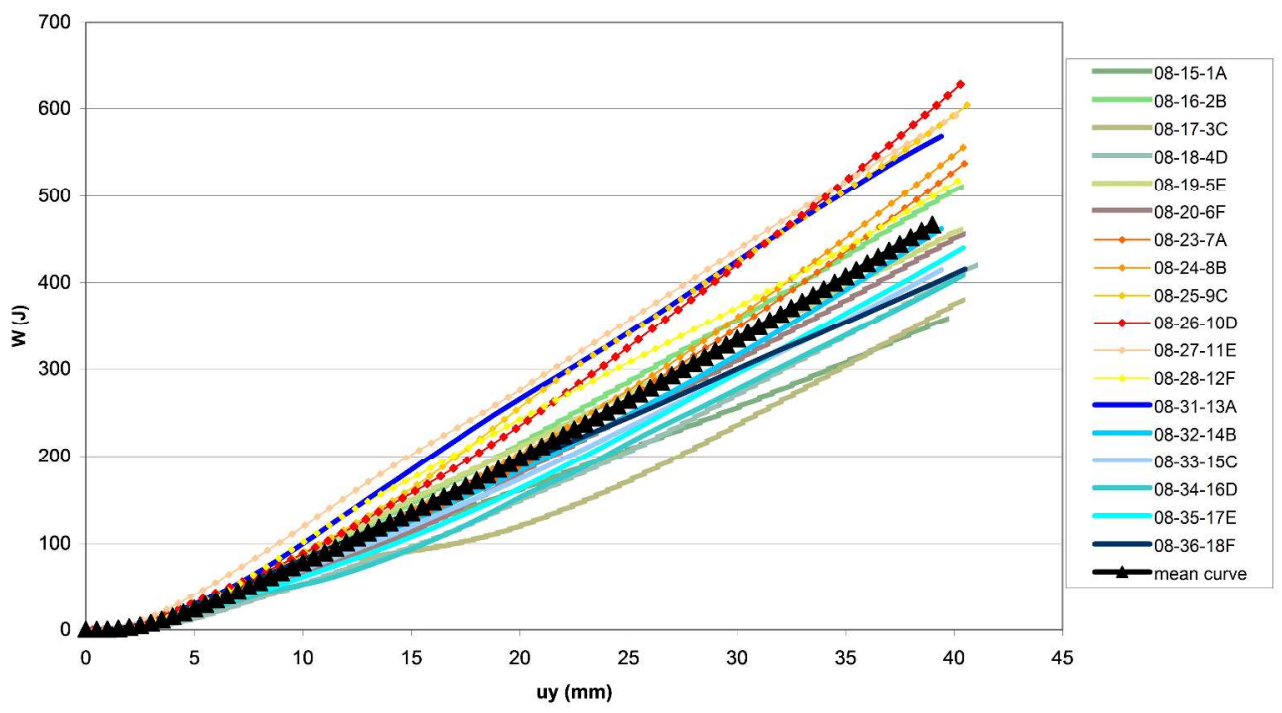

Figure 9: energy-penetration depth curves deduced from Figure 8 $514 \times 318 \mathrm{~mm}(300 \times 300 \mathrm{DPI})$ 


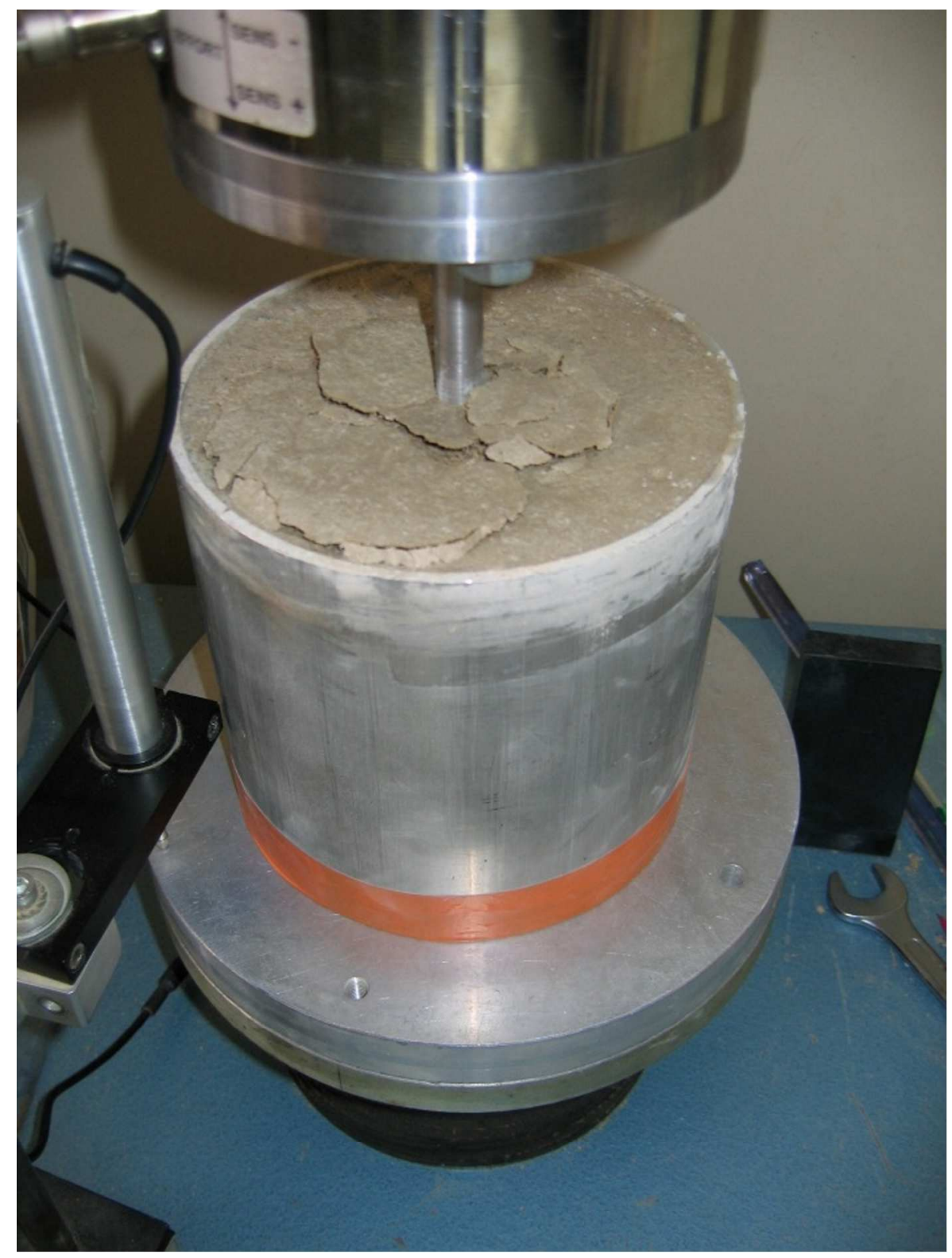

Figure 10: typical rupture of VLC $162 \times 216 \mathrm{~mm}(300 \times 300 \mathrm{DPI})$ 


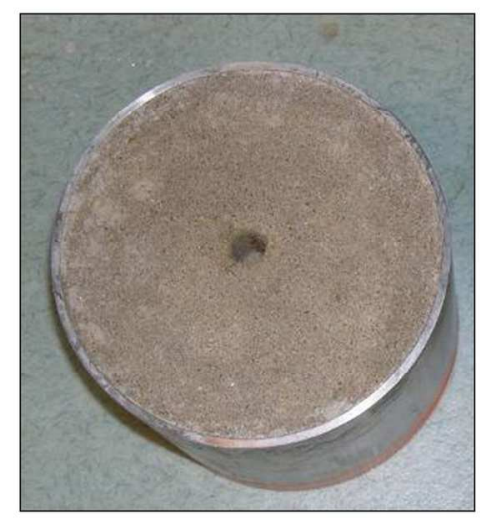

(a)

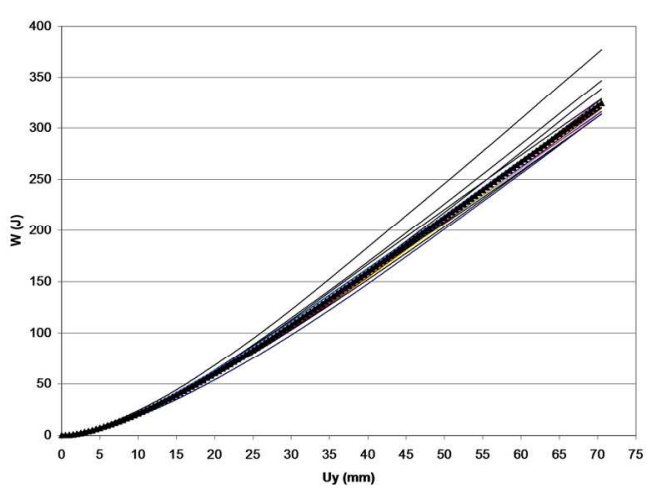

(b)

Figure 11: typical rupture of mortars with high volume of air entrained (a) and energy-penetration depth curves on different samples of the same mortar (b)

$172 \times 86 \mathrm{~mm}(300 \times 300$ DPI $)$ 